\title{
Comparison of the safety and efficacy of between second-generation and first-generation drug eluting stents in patients with left main coronary artery stenosis: A systematic review and meta-analysis
}

\author{
XiaoFei Gao ${ }^{1}$, Mei-Jun Liu ${ }^{2}$, and Yi-Zhou $\mathrm{Xu}^{2}$ \\ ${ }^{1}$ Hangzhou First People's Hospital \\ ${ }^{2}$ Affiliation not available
}

October 12, 2020

\begin{abstract}
Objective: The aim of this meta-analysis was to compare the safety and efficacy of second-generation and first-generation drug eluting stents (DES) for the treatment of left main coronary artery (LMCA) stenosis. Background: Studies have evaluated the safety and efficacy of between second-generation and first-generation DES in LMCA stenosis patients and the results of these studies were inconsistent. Methods: PubMed, EmBase and Cochrane Library were searched to identify eligible studies comparing the safety and efficacy of second-generation DES and first-generation DES for the treatment of LMCA stenosis. Odds ratios (ORs) with 95\% confidence intervals (CIs) were used to summary the estimates. Results: We identified 11 studies (1 was RCTs and 10 were observational studies) involving 4345 LMCA patients who treated with second-generation and first-generation DES. Second-generation DES had lower risk of MACE (15.4\% vs.18.5\%; OR 0.69 (0.52, 0.91); P=0.009), stent thrombosis $(1.1 \%$ vs.2.4\%; OR 0.46 (0.28, 0.74); P=0.001), TVR (6.8\% vs.13.4\%; OR 0.48 (0.35, 0.66); $\mathrm{P} \nmid 0.0001)$, and MI (1.6\% vs.3.5\%; OR $0.58(0.35,0.94) ; \mathrm{P}=0.03)$ compared with first-generation DES. There were no differences in the risks of all-cause mortality (6.8\% vs.7.9\%; OR 0.88 (0.68, 1.15); $\mathrm{P}=0.36)$, cardiac mortality (3.4\% vs.4.5\%; OR 0.73 (0.51, 1.03); P=0.07), and TLR (8.7\% vs.7.8\%; OR $1.09(0.86,1.39) ; \mathrm{P}=0.48)$ between second-generation and first-generation DES. Conclusions: In LCMA patients, compared with first-generation DES, second-generation DES was associated with lower risk of MACE, stent thrombosis, TVR, and MI. No differences were found with respect to all-cause death, cardiac death, and TLR. Key words: Second-generation stents; Drug-eluting stents; Percutaneous coronary intervention; Left main; Meta-analysis
\end{abstract}

\section{Hosted file}

3.pdf available at https://authorea.com/users/366278/articles/486348-comparison-of-thesafety-and-efficacy-of-between-second-generation-and-first-generation-drug-elutingstents-in-patients-with-left-main-coronary-artery-stenosis-a-systematic-review-and-metaanalysis

\section{Hosted file}

4.Figure1.eps available at https://authorea.com/users/366278/articles/486348-comparison-ofthe-safety-and-efficacy-of-between-second-generation-and-first-generation-drug-elutingstents-in-patients-with-left-main-coronary-artery-stenosis-a-systematic-review-and-metaanalysis

\section{Hosted file}

6.Figure 2a.eps available at https://authorea.com/users/366278/articles/486348-comparison-ofthe-safety-and-efficacy-of-between-second-generation-and-first-generation-drug-eluting- 
stents-in-patients-with-left-main-coronary-artery-stenosis-a-systematic-review-and-metaanalysis

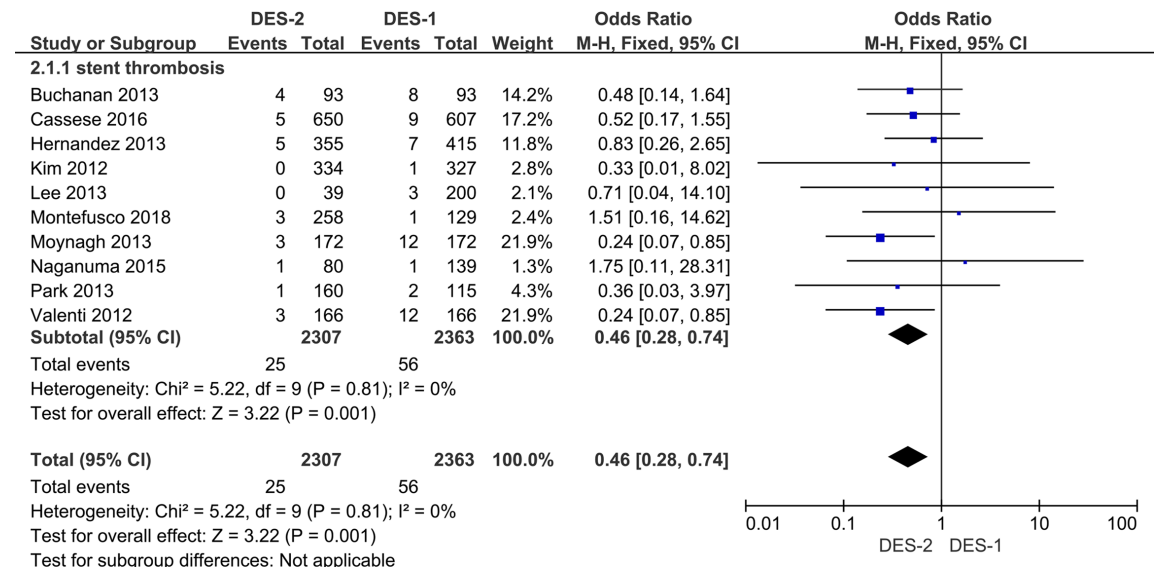




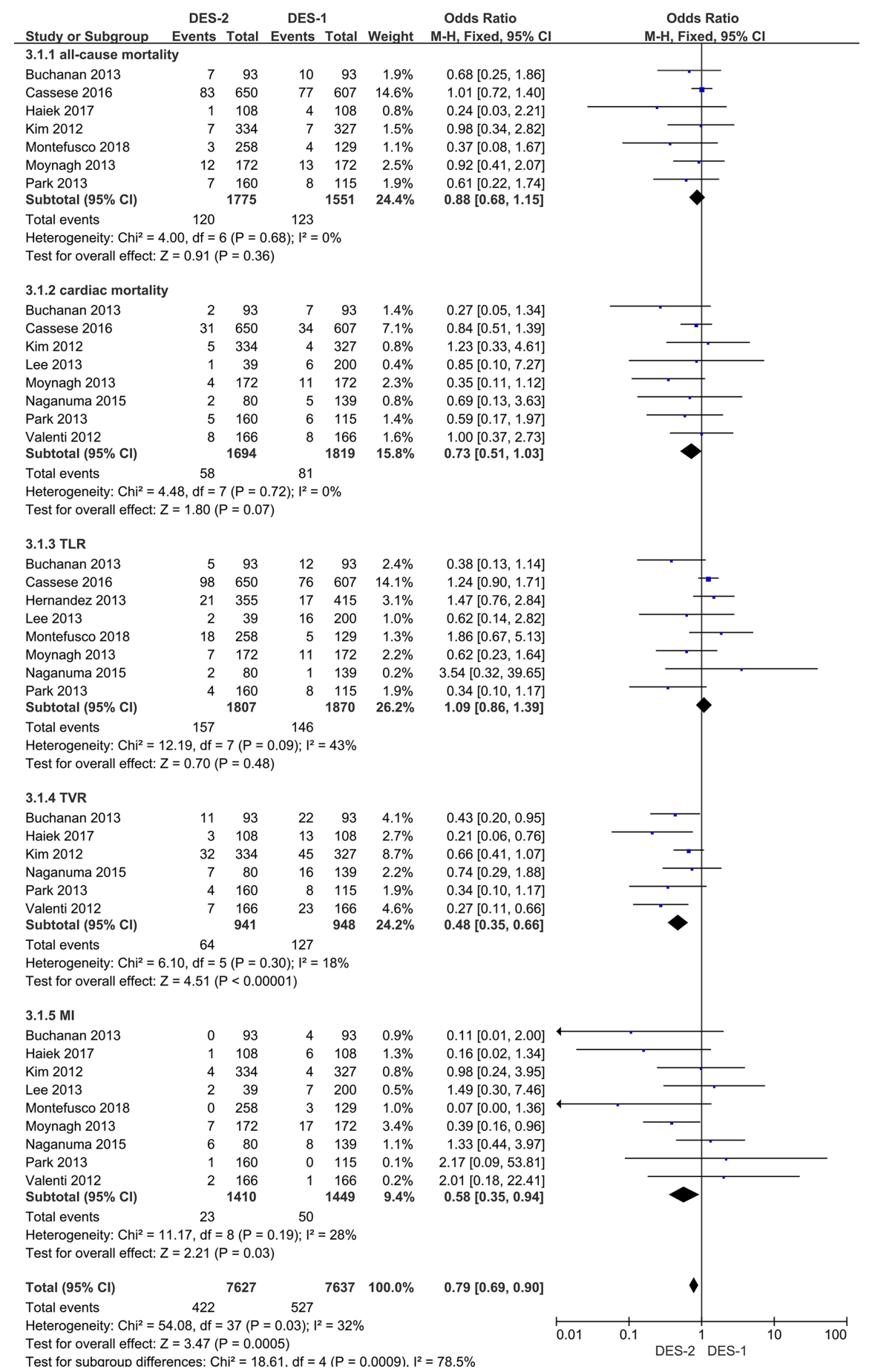




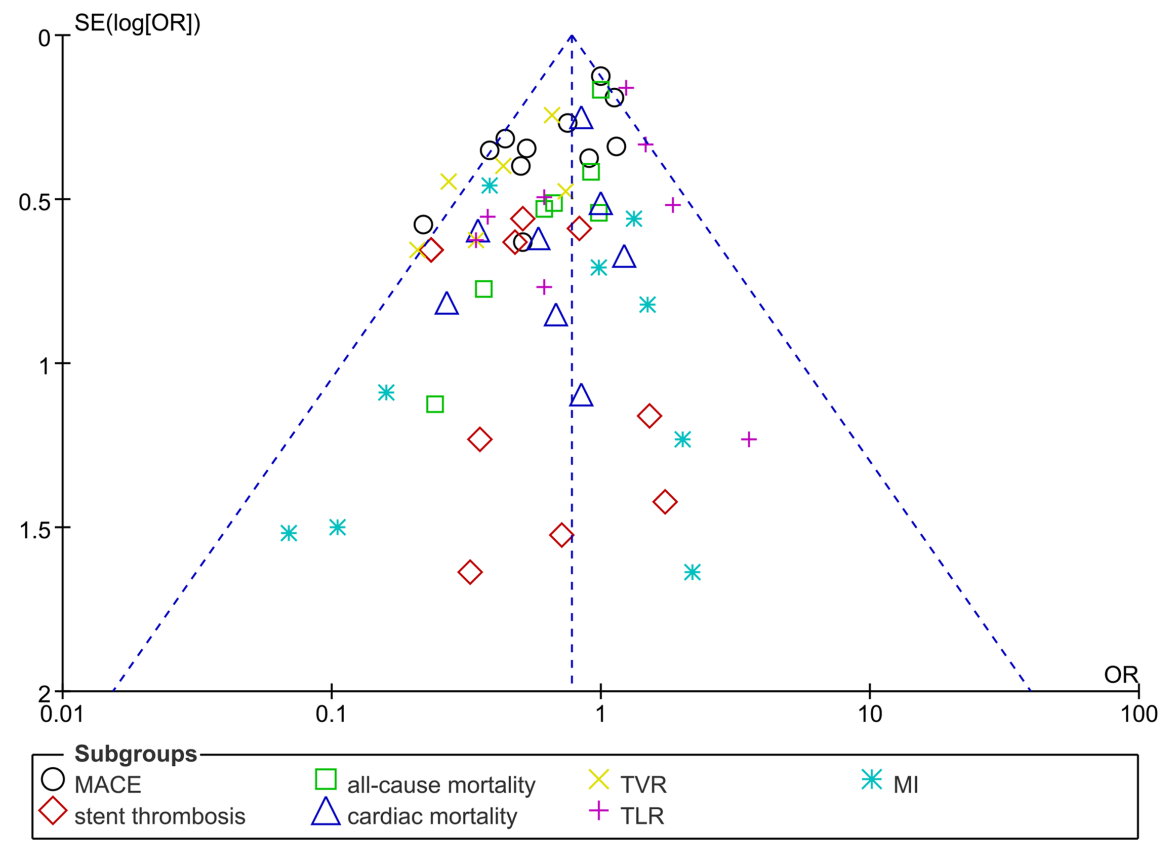

\section{Hosted file}

5.pdf available at https://authorea.com/users/366278/articles/486348-comparison-of-thesafety-and-efficacy-of-between-second-generation-and-first-generation-drug-elutingstents-in-patients-with-left-main-coronary-artery-stenosis-a-systematic-review-and-metaanalysis

\section{Hosted file}

5.pdf available at https://authorea.com/users/366278/articles/486348-comparison-of-thesafety-and-efficacy-of-between-second-generation-and-first-generation-drug-elutingstents-in-patients-with-left-main-coronary-artery-stenosis-a-systematic-review-and-metaanalysis

\section{Hosted file}

5.pdf available at https://authorea.com/users/366278/articles/486348-comparison-of-thesafety-and-efficacy-of-between-second-generation-and-first-generation-drug-elutingstents-in-patients-with-left-main-coronary-artery-stenosis-a-systematic-review-and-metaanalysis 